\title{
Effect of culture pH on cyanobacterial EPS composition: Implications for carbonate precipitation
}

\author{
MS. MARLISA MARTINHO DE BRITO, PHD $^{1}$, IRINA \\ BUNDELEVA $^{1}$, FRÉDÉRIC MARIN ${ }^{2}$, ANNICK \\ WILMOTTE $^{3}$, EMMANUELLE VENNIN ${ }^{1}$ AND PIETER T \\ VISSCHER $^{1,4}$ \\ ${ }^{1}$ University of Bourgogne Franche-Comté \\ ${ }^{2}$ CNRS - UMR6282 \\ ${ }^{3}$ University of Liège \\ ${ }^{4}$ The University of Connecticut \\ Presenting Author: marlisabrito5@gmail.com
}

Cyanobacteria are major contributors to precipitation of minerals forming biogenic carbonates. The photosynthetic activity of cyanobacteria increases $\mathrm{pH}$, favoring $\mathrm{CaCO}_{3}$ precipitation. These phototrophs produce copious amounts of exopolymeric substances (EPS) with a strong binding capacity for cations such as $\mathrm{Ca}^{2+}$ Environmental conditions (e.g., $\mathrm{pH}$ ) impact this cation binding and consequently influence properties of $\mathrm{CaCO}_{3}$ crystals. We hypothesize that $\mathrm{pH}$ has an additional important role in carbonate precipitation, namely by affecting cyanobacterial growth and EPS properties.

Different size fractions of EPS were extracted from the cyanobacterium Synechococcus elongatus PCC 7942 grown in both buffered and unbuffered medium (initial $\mathrm{pH} 7.5$; final $\mathrm{pH}$ 7.5 and 9.0 respectively). Large $(>10 \mathrm{kD})$ and small $(3-10 \mathrm{kD})$ EPS fraction were obtained from both growth conditions and properties, including total protein and total acidic sugar content were quantified. The molecular mass distribution of the fractions was determined by electrophoresis. Fourier-transform infrared spectroscopy analysis revealed a high sugar content $(40-55 \%$ of total) in EPS from buffered growth and a high protein content in EPS from the unbuffered medium. This difference in sugar:protein was further investigated in calcium carbonate inhibition/precipitation assays in the different EPS fractions. Forced precipitation experiments in all fractions obtained under different growth conditions revealed a change in $\mathrm{CaCO}_{3}$ crystal shape from small $(30-50 \mu \mathrm{m})$ rhombohedral to polycrystalline in protein-rich EPS to larger $(100 \mu \mathrm{m})$ rounded crystals in sugarrich EPS. Further analyses of these crystals showed that calcite formed at all EPS concentrations $(1-64 \mu \mathrm{g} / \mathrm{ml})$ tested but vaterite was only found in low (1-8 $\mu \mathrm{g} / \mathrm{ml})$ EPS concentrations.

We conclude that the environmental $\mathrm{pH}$ controls the mineral precipitation directly and indirectly. Directly, by affecting the cation binding capacity of EPS and mineral properties. Indirectly, $\mathrm{pH}$ alters cyanobacterial metabolisms, including the amount and acidity of the EPS produced. The sugar:protein ratio in Synechococcus EPS grown in different conditions results in a difference in acidity of the exopolymers. It is noteworthy that the cosmopolitan lifestyle of Synechococcus spp. in combination with our findings, may shed a clearer light on $\mathrm{CaCO}_{3}$ precipitation during whiting events on a global scale through geologic time. 